\title{
Penetrometer tests on 109 pit latrines in Kibera, Nairobi, Kenya
}

\author{
D Seal', RT Bown'2 and AH Parker ${ }^{1}$ \\ 'Cranfield Water Science Institute, Cranfield, Bedfordshire, MK43 OAL, United Kingdom \\ 2Innovia Technology, Cambridge, United Kingdom
}

\begin{abstract}
Pit latrine contents can have varying consistencies that make the pits challenging to empty. It has been assumed that solids sink to the bottom of the pit with a more liquid layer above this and a scum on the top. This implies that it would be possible to remove the uppermost layers with a pump. However, recent studies have found alternative sludge profiles, including a thick crust on the top. This paper presents penetrometer data from a large number (109) of pit latrines in Kibera, Nairobi, Kenya. The penetrometer consists of a weight, dropped onto an anvil that drives a cone into the pit. The depth of penetration following each impact was measured. This was converted into plots of depth in the pits against penetration. Each pit was analysed using Spearman's rank correlation coefficient, and categorised into positive or negative correlation, significant or non-significant. Significant, negative correlation was assumed to correspond to pits where the solids had sunk to the bottom. $38 \%$ of pits were classified in this way, which suggested that while it is common that the number of impacts required to penetrate the sludge increases with depth in the pit, this is not always the case. Pit emptiers should be prepared to deal with pits with a variety of sludge profiles, including those with a solids layer at the top.
\end{abstract}

Keywords: pit latrines, pit emptying, penetrometer

\section{INTRODUCTION}

Globally, 1.77 billion people use pit latrines as their primary means of sanitation (Graham and Polizzotto, 2013). A pit latrine is a lined or unlined pit into which users defecate, urinate and may also dispose of menstrual cloths, anal cleansing material and even household solid waste. Ideally it has a concrete or plastic slab to protect the top of the pit and provide a safe place for the user to stand (Tilley, 2014).

In rural areas, when the pit latrine is full it can often simply be covered over, a new pit can be dug and the superstructure moved to the new location. However, in dense urban settlements with limited space the pits must be emptied and their contents disposed of safely (Thye et al., 2011). Pit emptying can be a challenge because dense settlements may only provide narrow access routes for pit-emptying hardware (Thye et al., 2011), so they cannot be accessed by large truckmounted pumps. The sludge in the latrines varies in solids content. This can be due to the construction of the pit (lined pits will retain more water and their contents will be lower in solids content than unlined pits; Chirwa et al., 2017), the hydrogeology (highly permeable sandy soils will allow water to drain away more rapidly than clay soils, giving a high solids content), the amount of greywater that is also disposed of into the pit (Rottier and Ince, 2003) and the pit emptying regime (vacuum pumps can typically only empty watery layers, leaving solids to build up at the bottom, Radford and Fenner, 2013).

Pit sludge with a high solids content is challenging to remove with a mechanical pump (Buckley et al., 2008, Tilley et al., 2014). At present, these pits are emptied manually using shovels, presenting health hazards to the pit emptiers, depending on the personal protective equipment used (Thye et al., 2011).

\footnotetext{
To whom all correspondence should be addressed.

经 +441234750111

e-mail: a.parker@cranfield.ac.uk
}

Received 28 June 2017; accepted in revised form 13 June 2018
Various small-footprint technologies are being developed to empty pits. These include manually powered pumps (Thye et al., 2011), and smaller mechanically powered systems (Rogers et al., 2014). However, in order to fully understand the conditions in which these technologies will need to operate a greater understanding of the pit sludge and how it varies with depth is needed.

Until recently it was thought that solids sank to the bottom of the pit with a more liquid layer above this and a scum on the top (Bosch and Schertenleib, 1985; Pickford and Shaw, 1999; Heinss et al., 1999; Thye et al 2011; Chirwa et al., 2017). This hypothesis started to be challenged by Radford et al. (2014) who provided penetrometer data from 30 pits in Kampala, Uganda, and frequently observed thick crustal layers in pits. This paper further challenges this hypothesis with data and analysis from 109 pits in Kibera, Nairobi, Kenya.

\section{Study location}

Kibera is an informal settlement in Nairobi, Kenya. The population of Kibera slum is in dispute and estimates vary up to 1.5 million within an area of approximately $2.5 \mathrm{~km}^{2}$ (Veljanovski et al., 2012). The area carries one of the main Nairobi sewers through its centre but has very limited localised connectivity, so pit latrines are the main sanitation solution. Pit latrines serve between 2 and 350 people and have no common construction standard.

At the time of the research there were three pit-emptying teams operating within Kibera:

- The Kokima Self Help Group (KSHG) is a community-based organisation (CBO) operating a UN-Habitat funded Vacutug Mk II (shared between two other CBO's outside of Kibera).

The Vacutug is a mechanically powered vacuum pump with a $500 \mathrm{~L}$ tank, operating from a tractor and trailer.

- The Kara Company use a combination of hand techniques (i.e. shovels and buckets) and WSUP funded Gulpers (handoperated direct lift pumps).

- Small private organisation operating only within the Kiandi Village using hand-only techniques. 
All operators charged a standard cost per $100 \mathrm{~L}$ drum, regardless of time taken or difficulties encountered, resulting in an average charge of Ks 2 000-6 000 (24-71 USD) per pit emptying job. Although some of the pits surveyed were found to be beyond $3 \mathrm{~m}$ in depth, it is not common practise to have the pit 'emptied', but instead, on average, only two to four $100 \mathrm{~L}$ drums are removed each time.

\section{METHODOLOGY}

At the time of this research in 2012 no data were available to show the location of all the pit latrines in Kibera. Instead, using local maps 130 locations were selected at random and each visited to see if a pit latrine was present nearby. In 21 of the locations the only pits available discharged directly into local drains, so data were only collected from 109 pits.

A prototype penetrometer tool similar to a cone penetrometer (Stewart and Randolph, 1994) was manufactured in the UK prior to departure. The manufactured tool had a weight of $5.033 \mathrm{~kg}$, comprising of a penetration cone $(55 \mathrm{~mm}$ long $\times 35 \mathrm{~mm}$ diameter), at the base of a $15 \mathrm{~mm}$ diameter rod (four $750 \mathrm{~mm}$ sections, average $0.42 \mathrm{~kg}$ ) with a maximum penetration depth of $3 \mathrm{~m}$ (see Fig. 1). The means of applying a consistent penetration impulse was through impact, via a weight of $1.982 \mathrm{~kg}$ dropped repeatedly from a set height of $45 \mathrm{~cm}$ onto a $0.728 \mathrm{~kg}$ anvil. The depth of penetration after each impact was measured and recorded.

To establish the correct impact weight, 3 penetration tests were conducted on 2 latrines, at each of the 4 weights available (1.982 kg plus 3 additional single weights, each at $1 \mathrm{~kg}$ ) to gauge the appropriate impact pressure for a penetration rate that could be consistently measured. The single $1.982 \mathrm{~kg}$ weight provided slower penetration within softer sludge at smaller measurements, and was used for the remainder of data collection.

At each location, the slab depth and depth to excreta were measured. The penetration head with 2 rods connected was lowered into the pit until the rods ceased falling under their own weight (more rods were added if required) and a

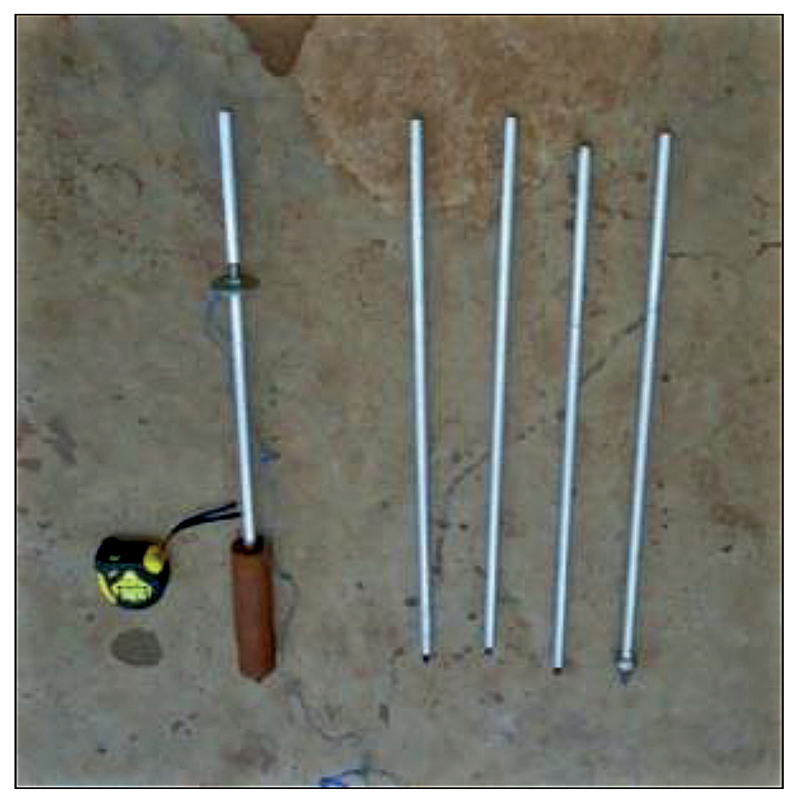

Figure 1

Cone penetrometer components penetration reading taken. The drop weight section (with anchor line to prevent loss from rapid dropping) was added and a measurement taken following movement ceasing (see Fig. 2). More rods were added if required. If full penetration was not achieved, the weight was repeatedly lifted and dropped with more rods added when needed, until full penetration was achieved. Once further penetration was not achieved by repeated dropping of the weight, additional manual pressure was applied to ascertain if further movement was possible (i.e. to check if the cone had reached the bottom of the pit) and if there was further movement, the test was restarted away from the original point of penetration.

Upon retrieval of the tool, all rods were cleaned, initially using tissue to remove the majority of excreta during extraction, and then a cloth with a mild bleach solution was used to remove the remaining excreta and sanitise the equipment. Use of the penetrometer is a 2-person operation (operator and a logger), who each wore a mask and thick protective rubber gloves. Appropriate vaccinations are recommended for the research team. The rim of the pit was wiped down and care was taken to prevent any further contamination of the area surrounding the pit.

\section{Analysis}

The measurement of the depth of the cone with each impact was converted into plots of depth in the pits against penetration per impact by subtracting each measurement from the preceding one. However, from a visual inspection of these plots it is hard to spot any trends; the pits also have a varying number of data points; however pits with a small number of data points are no less significant than those with a large number of data points. The authors were keen to avoid any visual or manual interpretation and instead decided to use Spearman's

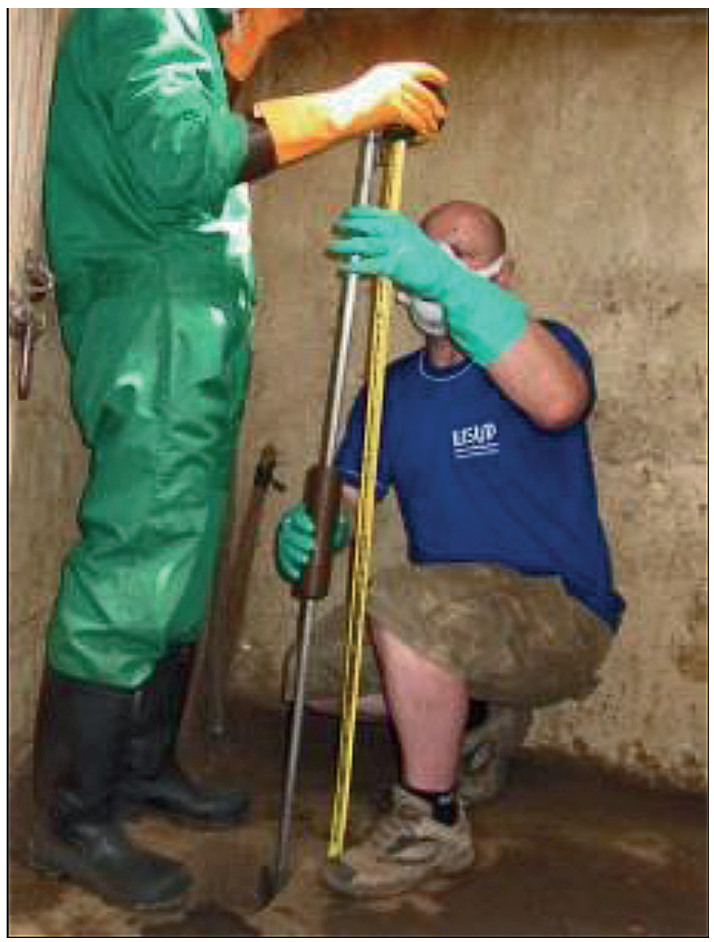

Figure 2

Cone penetrometer in use 
rank correlation coefficient which describes how well the relationship between two variables can be described using a monotonic function. This allowed the testing of the hypothesis that solids sink to the bottom of the pit. Assuming that higher solids content material required more impacts to penetrate it, then pits displaying a significant negative correlation support the hypothesis.

For each pit where 4 or more impacts were required, Spearman's rank correlation coefficient was calculated. Each pit was recorded as having either significant positive, significant negative, non-significant positive or non-significant negative correlation.

\section{RESULTS}

The Appendix (Fig. A1) provides a compilation of all 109 pits, which shows the depth in the pits against penetration per impact. It shows the huge variety in the pits sampled. Apparently blank plots show where the penetrometer sunk to the bottom of the pit with one impact. Plots with one point mean only 2 impacts were required for the penetrometer to reach the bottom of the pit.

The results of the classification by Spearman's rank correlation coefficient of depth in the pits against penetration per impact are presented in Fig. 3. The largest category was the significant negative correlation, with 42 pits (38\%) being classified in this way. The second largest category was pits with 4 or fewer impacts, i.e. 29 pits (26\%). Only 16 pits $(15 \%)$ had a positive correlation.

\section{DISCUSSION AND CONCLUSION}

A significant positive correlation means that the sludge became easier to penetrate with depth, and could mean there is a consolidated scum layer on top. An alternative interpretation is that the penetrometer hit a piece of solid waste (e.g. a bottle) which took several impacts to move out of the way. Pits where
4 or fewer impacts were required could be interpreted as having watery sludge which is more likely to be pumpable by a vacuum pump.

In $38 \%$ of pits there was a significant negative correlation of depth in the pits with penetration per impact, which means the number of impacts required to penetrate the sludge increases with depth in the pit. This could be interpreted as an increase in the solids content with depth, supporting the hypothesis proposed by Bosch and Schertenleib (1985), Pickford and Shaw (1999) Heinss et al. (1999), and Thye et al. (2011). Radford (2014) used a similar penetrometer and linked the number of impacts to shear strength, concluding that the higher the shear strength, the harder it would be to empty. A further $19 \%$ of pits display a non-significant negative correlation.

However, there is a limitation of this analysis related to the fact that a data point is only recorded when an impact is made. When a thick layer that was easy to penetrate was encountered, the penetrometer would fall through easily, potentially requiring only 1 impact. This produces a spike in the plot in Fig. 3. In Spearman's rank correlation coefficient, each point has an equal value, so these points are treated in the analysis as outliers, rather than as significant data points. This will lead to an overestimate of the number of pits displaying significant negative correlation.

A further limitation of the data collection was that some pits may have been deeper than $3 \mathrm{~m}$, so the bottom-most part was not sampled. Most pit owners and users did not know the full constructed depth of the pit. However, often only the top portion of the pit is emptied; for example, the Vacutug can only reach to $1.4 \mathrm{~m}$, and the Gulper to $2 \mathrm{~m}$, so this upper data is the most relevant for informing pit emptying.

Strategies to make pits easier to empty are required and further studies on in-pit fluidisation, extending the work of Radford and Sugden (2014), are welcomed, as long as they evaluate both the source of water in water-scarce areas and the subsequent treatment of an additional volume of faecally contaminated water. Reducing the disposal of household waste

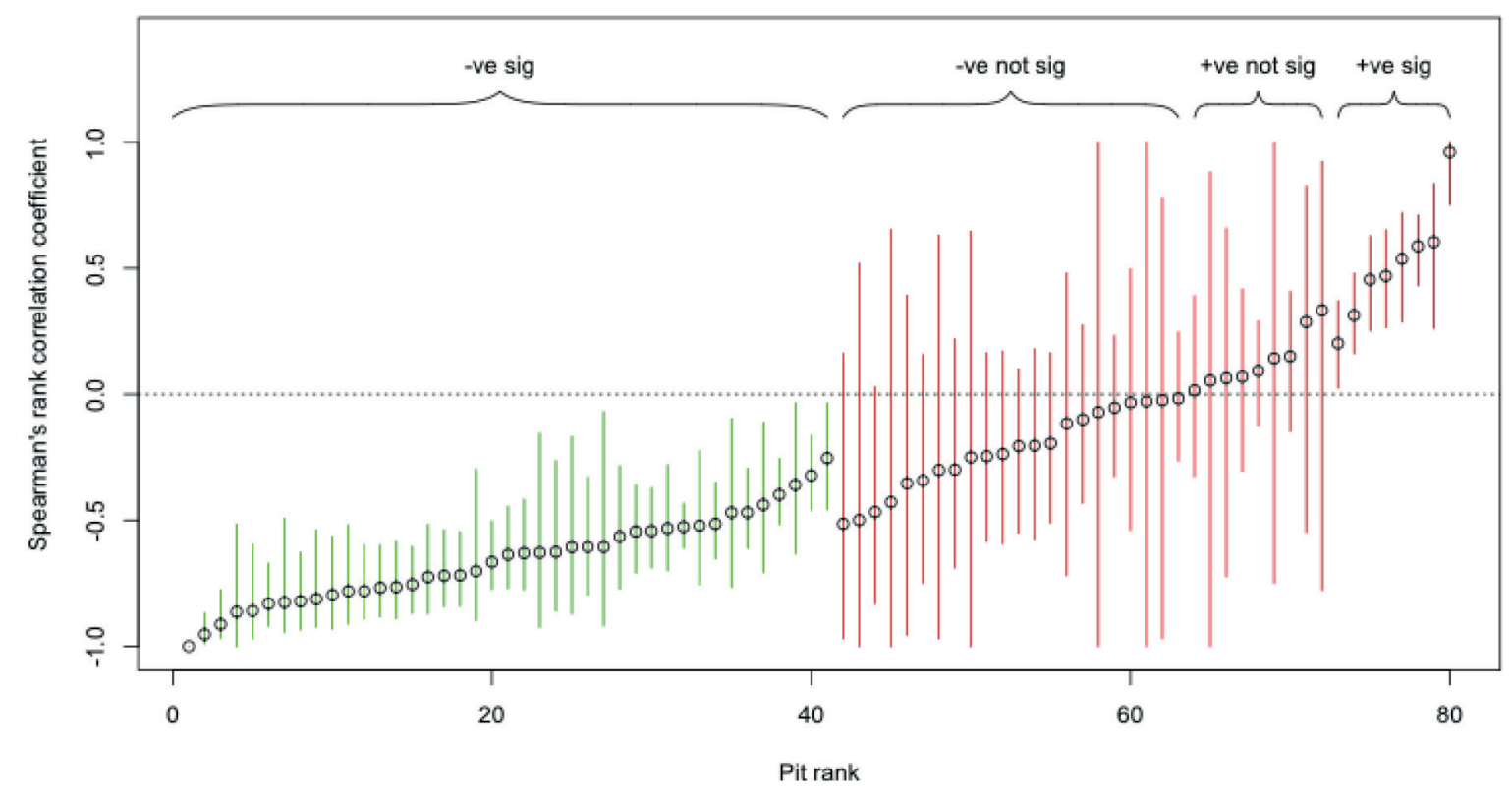

Figure 3

Spearman's rank correlation coefficient for the data collected in each pit, classified by the type of correlation. The error bars are $95 \%$ confidence intervals. Note: the 29 pits where there were 4 or fewer impacts are excluded. 
in latrines would also help - in $40 \%$ of the latrines in this study household waste was visible, and it may have simply been concealed by the sludge in the remaining $60 \%$.

Overall, this research has highlighted that while it is common that the number of impacts required to penetrate the sludge increases with depth in the pit, this is not always the case. As more impacts are required to penetrate the sludge, the harder it will be to remove the sludge from the pit (Radford and Sugden, 2014); this has a direct impact on pit emptying. Service providers should not assume that you can always just remove the uppermost watery layers, and should be prepared to empty pits containing more solid material which might extend throughout or be in the uppermost layers. This is particularly true in locations where there has been no regulation of pit construction, and pits could be unlined, fully lined or partially lined, and could receive varying amounts of greywater, both impacting the sludge consistency. Future research needs to investigate how these factors affect sludge; this needs to be carried out in an area where pit structures are well documented or potentially in a controlled environment.

\section{ACKNOWLEDGEMENTS}

Water and Sanitation for the Urban Poor (WSUP) are acknowledged for their sponsorship of the project. Gerald (WSUP Nairobi) and Rajab and Abdul (Kara Company) are thanked for their assistance in data collection.

\section{REFERENCES}

BOSCH A and SCHERTENLEIB R (1985) Emptying on-site excreta disposal systems: Field tests with mechanized equipment in Gaborone (Botswana). IRCWD Report 03/85. IRCWD, Duebendorf, Switzerland.

BUCKLEY CA, FOXTON KM, BROUCKART CJ, RODDA N, NWANERI C, BALNOBI E, COUDERC A and MAGAGNA D (2008) Scientific support for the design and operation of ventilated improved pit latrines (VIPs) and the efficiency of pit latrine additives. WRC Report No. TT 357/08. Water Research Commission, Pretoria.
CHIRWA CFC., HALL RP, KROMETIS LH, VANCE EA, EDWARDS A, GUAN T and HOLM RH (2017) Pit latrine fecal sludge resistance using a dynamic cone penetrometer in low income areas in Mzuzu City, Malawi. Int. J. Environ. Res. Public Health 1487. https://doi.org/10.3390/ijerph14020087

GRAHAM JP and POLIZZOTTO ML (2013) Pit latrines and their impacts on groundwater quality: a systematic review. Environ. Health Perspect. 121 (5) 521-530. https://doi.org/10.1289/ ehp. 1206028

HEINSS U, LARMIE SA and STRAUSS M (1999) Characteristics of Faecal Sludges and their Solids-Liquid Separation. EAWAG/ SANDEC, Duebendorf, Switzerland.

PICKFORD J and SHAW R (1999) Emptying pit latrines. Technical Brief No. 54. In: Shaw R (ed.) Running Water. IT Publications, UK. RADFORD JT and FENNER RA (2013) Characterisation and fluidisation of synthetic pit latrine sludge. J. Water Sanit. Hyg. Dev. 3 (3) 375-382. https://doi.org/10.2166/washdev.2013.023

RADFORD JT and SUGDEN S (2014) Measurement of faecal sludge in-situ shear strength and density. Water SA 40 (1) 183-187. https:// doi.org/10.4314/wsa.v40i1.22

ROGERS TW, DE LOS REYES III FL, BECKWITH WJ and BORDEN RC (2014) Power earth auger modification for waste extraction from pit latrines. J. Water Sanit. Hyg. Dev. 4 (1) 72-80. https://doi. org/10.2166/washdev.2013.183

ROTTIER E and INCE ME (2003) Controlling and preventing disease: The role of water and environmental sanitation interventions WEDC, Loughborough University, UK.

STEWART DP and RANDOLPH MF (1994) T-Bar penetration testing in soft clay. J. Geotech. Eng. 120 (12) 2230-2235. https://doi. org/10.1061/(ASCE)0733-9410(1994)120:12(2230)

TILLEY E, ULRICH L, LUTHI C, REYMOND P and ZURBRUGG C (2014) Compendium of Sanitation Systems and Technologies $\left(2^{\text {nd }}\right.$ edn). Swiss Federal Institute of Aquatic Science and Technology (Eawag), Dübendorf, Switzerland.

THYE YP, TEMPLETON MR and ALI M (2011) A critical review of technologies for pit latrine emptying in developing countries. Crit. Rev. Environ. Sci. Technol. 41 1793-1819. https://doi.org/10.1080/10 643389.2010.481593

VELJANOVSKI T, KANJIR U., PENHANI P, OSTIR K and KOVACIC P (2012) Object-based image analysis of VHR satellite imagery for population estimation in informal settlement Kibera-Nairobi, Kenya. In: Escalante B (ed.) Remote Sensing - Applications. InTech, Rijeka, Croatia. 


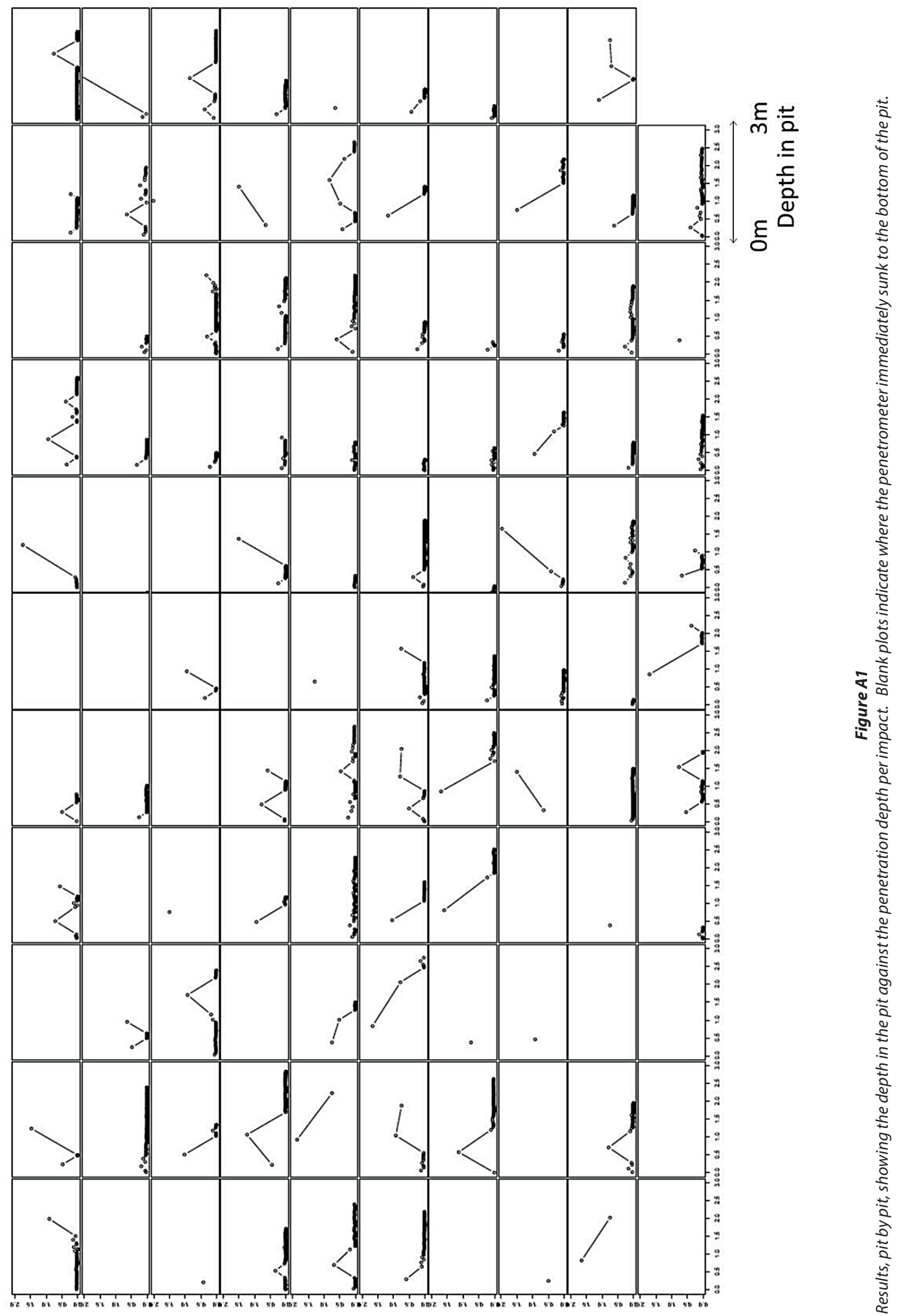

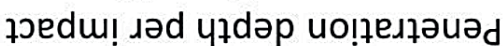

